DíEz PALACios, D., «La cosa de uso colectivo en los primeros niveles sociales: sociedad de banda y sociedad segmentaria», REDUR 17, diciembre 2019, págs. 23-44. ISSN 1695-078X. doi: 10.18172/redur.4493

\title{
LA COSA DE USO COLECTIVO EN LOS PRIMEROS NIVELES SOCIALES SOCIEDAD DE BANDA Y SOCIEDAD SEGMENTARIA
}

\author{
DiEGo DÍEZ PALACIOS \\ ProfESor AyUdANTE DE DERECHO Romano \\ UNIVERSIDAD AUTÓNOMA DE MADRID \\ diego.diez@uam.es
}

SUMARIO: I. INTRODUCCIÓN; II. ESTRUCTURA INTERNA DE LAS FORMACIONES JURÍDICO-POLÍTICAS DESDE EL INICIO SOCIAL. II.A) RECORRIDO GENERAL Y TEORÍAS. II.B) VARIAS REFLEXIONES SOBRE LA FAMILIA Y LA GENS A LA LUZ DE LAS TEORÍAS DOCTRINALES. III. EXPRESIÓN DE LA COSA DE USO COLECTIVO EN LOS PRIMEROS NIVELES DE LA ORGANIZACIÓN JURÍDICO-POLÍTICA. III.A) ESQUEMA TEÓRICO. III.B) SOCIEDAD DE BANDA Y COSA DE USO COLECTIVO. III.C) SOCIEDAD SEGMENTARIA Y COSA DE USO COLECTIVO. IV. A MODO DE EPÍLOGO.

RESUMEN: Este artículo pretende estudiar la cosa de uso colectivo en los dos primeros niveles que atraviesa la sociedad desde su origen — sociedad de bandas y sociedad segmentaria - al tiempo que extraer sus notas informadoras para estos periodos. Esta investigación servirá para comprender de un modo completo la expresión de la cosa colectiva en tiempos históricos. La finalidad de este estudio es abordar de un modo completo la futura investigación de la cosa de uso colectivo en la experiencia jurídica romana donde se encuentra el fundamento histórico de nuestra actual institución jurídica del dominio público.

Palabras Clave: cosa colectiva de uso colectivo, sociedad, Derecho, sociedad de banda, sociedad segmentaria.

\section{THE COLLECTIVE USE THING IN THE FIRST SOCIAL LEVELS BAND SOCIETY AND SEGMENTARY SOCIETY}

ABSTRACT: This article aims to study the thing of collective use in the first two levels that the society goes through from its origin - society of bands and segmentary society- while extracting its informative notes for these periods. This research will serve to understand in a complete way the expression of the collective thing in historical times. The purpose of this study is to address in a complete way the future investigation of the thing of collective use in the Roman legal experience where the historical foundation of our current legal institution of the public domain is found.

KEYWORDS: Collective use thing, society, law, band society, segmentary society. 


\section{Introducción}

La búsqueda del origen de todo fenómeno o institución jurídica conlleva inevitablemente una investigación que en la mayoría de ocasiones obliga, con el estado actual de las fuentes e independientemente del campo de trabajo, a extender su tarea reconstructiva por ámbitos de estudio ajenos al objetivo de análisis ${ }^{1}$. Las diferentes instituciones o fenómenos se presentan ante el estudioso en un estado alcanzado de cierto desarrollo. En este sentido son apreciables las palabras de Moret-Davy cuando afirma que los primeros puntos fijados de la cronología de una institución o fenómeno nunca corresponden con los primeros tanteos del progreso y nos presentan solo una figura que tiene un largo pasado tras ella ${ }^{2}$.

El pasado es un estado esencial y básico para comprender la expresión de cualquier fenómeno o institución. Ahora bien, para afrontar de un modo satisfactorio o para comprender adecuadamente una figura en una época conocida es condición obligatoria retrotraerse a sus orígenes que bien pueden encontrarse, como veremos en el caso de la cosa de uso colectivo, en el origen social. Del mismo modo es condición indispensable volver sobre sus primeras manifestaciones. Por lo que a estas respecta deben ser consideradas como lugares espaciales y temporales donde el fenómeno comienza a forjar una serie de rasgos característicos que irán, conforme la sociedad evoluciona, perfeccionándose, asentándose y haciendo posible el acceso de la figura a la posición institucional. Se comprende, por lo tanto, que para conocer un instituto en plenitud debe hacerse un análisis de su origen y desde él, de sus primeras manifestaciones de forma que podamos ir conectando tiempos a la luz del desarrollo fenomenológico estudiado.

La figura o fenómeno que vamos a analizar es la cosa colectiva de uso colectivo. Su generación se produce en el momento del nacimiento social como un elemento esencial e irresistible a todo grupo humano. Ahora bien, sus expresiones variaran dependiendo del ambiente, en sentido amplio, en el que la comunidad se desarrolle. No obstante, su grado evolutivo puede comprender, hasta cierto momento, una línea o ley general a partir de la cual el elemento diferenciador, fruto de cada formación socio-jurídica, marcará la dirección de las expresiones de una forma peculiar para cada sociedad. A continuación, estudiaremos, enmarcado en los dos primeros niveles de sociabilidad — sociedad de banda y sociedad segmentaria-, la expresión, la perfección y el desarrollo de la cosa de uso colectivo. Este trabajo será, por lo tanto, un fundamento que permita en momentos posteriores realizar una investigación eficaz de la cosa de uso colectivo en la experiencia jurídica romana haciendo comprender ciertos rasgos que la misma desarrolla y perfecciona de un modo excelente, a través del Derecho Romano, en momentos plenamente históricos.

La nueva realidad social, creada en el origen de la formación jurídico-política para dar satisfacción a las necesidades de la vida en comunidad, debe ser colocada en una posición de relación entre esta y sus modos de articulación, es decir, la familia y después,

\footnotetext{
${ }^{1}$ Sobre la importancia de analizar campos académicos ajenos al objeto de estudio para comprender y dar plenitud, en este caso al Derecho Romano, ámbito al que se dirige esta investigación, uno por todos, vid. FERNÁNDEZ DE BUJÁN, A., Derecho Público Romano. Vigésimo segunda edición (Pamplona 2019) 43.

2 MORET-DAVY, De los clanes a los imperios. La organización social entre los primitivos y en el oriente antiguo, trad. esp. De la Torre (Barcelona 1925) 5.
} 
tras la reunión de familias, la gens. Veremos cómo los modos de organizar una sociedad son diferentes a los niveles sociales y como estos inciden en la evolución de la cosa. Además, queda excluida la noción de Estado como organización social necesaria para hablar de cosa de uso colectivo. Este solo será un estadio evolutivo de la propia sociedad.

En síntesis, el objetivo propuesto es analizar la cosa de uso colectivo a la luz de las primeras fases del curso social, fijar su trayectoria, encontrar sus expresiones, observar la transición fásica y reconocer sus caracteres. Con ello no haremos sino preparar el camino a la comprensión de esta figura en la experiencia jurídica y social romana donde, como es conocido, la cosa de uso colectivo gracias a su régimen o regulación informativa y a su excelente proyección material propiciaron, en esta sociedad, una forma de vida y en sus territorios una unidad.

\section{Estructura interna de las formaciones jurídico-políticas desde el inicio social}

II.a) Recorrido general y teorías

La cosa de uso colectivo, como hemos indicado más arriba, depende de la sociedad. Para poder elaborar y comprender en su conjunto la evolución de nuestro objeto de estudio será necesario previamente exponer el cuadro que la antropología, la arqueología, los estudios políticos y la investigación jurídica han elaborado sobre las formas de organización política $^{3}$. Ahora bien, como puso de relieve Fuenteseca ${ }^{4}$, la estructura social primitiva siempre es difícil de determinar si bien, siguiendo Bonfante ${ }^{5}$, toda la historia de la propiedad primitiva es historia de propiedad colectiva. Precisaremos estas afirmaciones.

Los modelos clásicos de formación jurídico-política, originados por lo general en el siglo XIX y desarrollados en la primera mitad del siglo XX, propugnan una progresión o sucesión social que comienza con unos modelos de organización humana concretos y se dirige hacia formas totalmente diversas al propio tiempo que correlativas entre sí, sobre todo en ciertos aspectos de su organización ad intra y su expresión ad extra. Estos modelos no fijan el Estado como esquema social básico y punto necesario de partida, ya sea en un ejercicio prospectivo o retrospectivo de actividad, ni mucho menos le asignan una situación de origen pura, si bien es cierto que su entidad es colocada como centro del desarrollo social y/o como punto culminante de su llegada. En este sentido, el problema ha sido abordado desde un doble punto de vista en el que prima el aspecto temporal: el Estado es anterior a

\footnotetext{
3 Vid. nt.53.

4 FUENTESECA, Mancipium-mancipatio-dominium, en Labeo, 4, 1958, 135.

${ }^{5}$ BONFANTE, Forme primitive ed evoluzione della propietà romana (Res mancipi e res nec mancipi), en Scritti Giuridici Varii, II. Propietà e servitù, Torino, 1918, 3.
} 
otros grupos sociales como la gens y la familia6, o es posterior y consecuencia de estos7. Asimismo, habiendo establecido la localización espacio temporal de cada grupo social familia, gens, Estado (Bonfante, Engels); Estado, gens, familia (Meyer, Coli) — la doctrina procede a analizar su naturaleza y establece posiciones que oscilan, teniendo en cuenta la primera división, entre la teoría patriarcal8, que toma su nombre de la influencia bíblica basada en los patriarcas hebreos del Asia menor ${ }^{9}$ como Abraham, Isaac o Jacob cuya actividad ha quedado plasmada en libro del Génesis donde la familia deriva de un vínculo sanguíneo basado en el matrimonio y responde a la autoridad absoluta del patriarca; la teoría política ${ }^{10}$, que reconoce un elemento esencial de tipo político en la condición y

${ }^{6}$ El principal exponente de esta teoría es MEYER, Geschichte des Alterthums. Forschungen zur alten Geschichte, II, 1899, 514 ss.; Ueber die Anfänge des Staats und sein Verhältniss zu den Geschlechtsverbänden und zum Volksthum, en Sitzungsberichte der Königlich preussischen Akademie der Wissenschaften zu Berlin, Berlin, 1907, 1, 508 ss. Las bases de la teoría de Meyer quedan sintetizadas por BONFANTE, Teorie vecchie e nuove sulle formazioni sociali primitive, en Scritti Giuridici Varii, I. Famiglia e successione. Torino, 1916, 27, en tres puntos: 1․ El Estado, aunque en forma de horda, es el organismo primitivo que nace con el hombre. La familia, la gens son formadas dentro del Estado y por obra del Estado. $2^{ }$․ La humanidad antigua presenta una multiplicidad de grupos y de relaciones sociales, que se superponen cruzándose y entrelazándose. De estos uno solo merece el nombre de Estado, los otros se consideran subdivisiones de este y deben por regla su origen a la escisión de grupos mayores, a la desmembración de Estados preexistentes. 3ํ. No hay ninguna antítesis esencial entre la sociedad primitiva y la sociedad posterior, ninguna influencia esencial del territorio sobre el concepto de Estado.; Desde un punto de vista económico defienden esta teoría, VOCI, Esame delle tesi del Bonfante su la Famiglia Romana Arcaica, en Studi in onore di Vicenzo Arangio Ruiz, I, 1952, 101 ss.; ARANGIO RUIZ, Le genti e la città, II, en Annuario della Università di Messina, 1913-1914, 11 ss.= Le genti e la città, en Scritti Giuridici raccolti per il centenario della Casa Editrice Jovene 1854-1954, Napoli, 1954, 110 ss.; Desde el punto vista del regmun y el poder del imperium, todo ello relacionado con un Nomen Latinum o Estado Federal Latino, COLI, Regnum, en Studia et Documenta Historiae et Iuris, 17, 1951.

7 BONFANTE, Teorie vecchie e nuove sulle formazioni sociali primitive, en Scritti Giuridici Varii, I. Famiglia e successione. Torino, 1916, 1 ss.; La «gens» e la «familia», en Scritti Giuridici Varii, I. Famiglia e successione. Torino, 1916, 1 ss.; L'origine dell' «Hereditas» e dei «Legata» nel diritto successorio romano, en Scritti Giuridici Varii, I. Famiglia e successione. Torino, 1916, 101 ss.; Le affinità giuridiche greco-romane, en Scritti Giuridici Varii, I. Famiglia e successione. Torino, 1916, 337 ss.; Forme primitive ed evoluzione della propietà romana (Res mancipi e res nec mancipi), cit., 1 ss.; Corso de Diritto Romano, I. Diritto di famiglia (Milano 1963).; ENGELS, Origen de la familia, de la propiedad privada y del Estado (Madrid 1891) 34 ss.

8 BONFANTE, Teorie vecchie e nuove sulle formazioni sociali primitive, en Scritti Giuridici Varii, I. Famiglia e successione. Torino, 1916, 21, compendia en tres los puntos de esta concepción: 1‥ La célula de la sociedad humana es la familia, en consecuencia, la base de la aglomeración social primitiva es el vínculo familiar de parentela o de sangre. $2^{\circ}$. Los grupos mayores son constituidos por expansión natural, por agregación de familias, por federaciones de los grupos menores. Así paulatinamente se desarrolla la gens, la tribu, la ciudad, el Estado. $3^{\circ}$. La organización política surge con el paso del tiempo en la ciudad y en el Estado por influencia del territorio, es decir, de la estable convivencia de individuos de diverso origen en una sede común. Otros defensores de esta teoría son MOMMSEN, Römische Forschungen, I (Berlín 1864) 71 ss.; VICO, Principi di scienza nuova, ed. Nicolini 1942, I, 24 ss.; II, 377 ss.; SUMNER MAINE, El Derecho Antiguo. Parte General, cit., 87 ss.; FUSTEL DE COULANGES, La ciudad antigua, ed. Península (Barcelona 1984) 64 ss., quien además de reconocer el vínculo sanguíneo en la generación familiar otorga al factor religioso un importante papel en la formación social del grupo.; IHERING, El Espíritu del Derecho Romano en las diversas fases de su desarrollo, trad. esp. Príncipe Satorres (Granada 1998) 139 ss.; PIGANIOL, Histoire de Rome, en Clio. Introduction aux Études Historiques, 3. Presses universitaires de France, 1939.

${ }^{9}$ Cfr. SUMNER MAINE, El Derecho Antiguo. Parte General, cit., 87 s.; LAMBERT, La tradición romana sobre la sucesión de formas del testamento ante la historia comparada, trad. esp. García Herreros (Madrid 1903) 17 nt.1, refiere el sistema jurídico hebraico, por el método comparado, como uno de los filones de acontecimientos de los más preciosos a que puede acudir el historiador del derecho comparado.

10 DE RUGGIERO, La gens in Roma avanti la formazione del comune, en Critica e scienza positiva, Napoles, 1872.; BONFANTE, La «gens» e la «familia», cit., 1 ss.; Teorie vecchie e nuove sulle formazioni sociali primitive, cit., 18 ss.; L'origine dell' «Hereditas» e dei «Legata» nel diritto successorio romano, cit., 101 ss.; Le affinità giuridiche greco-romane, cit., 337 ss.; Forme primitive ed evoluzione della propietà romana (Res mancipi e res nec mancipi), cit., 1 ss.; Corso de Diritto Romano, I. Diritto di famiglia, cit.; Adheridos a esta concepción política 
carácter de la organización familiar precívica y que bien puede encuadrarse en un solo tipo junto a la teoría patriarcal y, por último, la teoría económica ${ }^{11}$, donde el elemento económico es el impulso y la base del grupo social familiar pre-urbano.

II. b) Varias reflexiones sobre la familia y la gens a la luz de las teorías doctrinales

Ante este cuadro de teorías llama la atención como la gran mayoría de autores cataloga en primer lugar la familia y por esta la gens para desde ellas llegar al Estado. Parten, por lo tanto, a excepción de Meyer y Coli12, como máximos representantes de la posición contraria, de la precedencia de la familia y la gens al modelo Estatal. En nuestra opinión el Estado es posterior al grupo familiar y al grupo gentilicio. Ahora bien, hacemos notar como la familia o la gens, cuando ésta despunte en el tejido social, serán los núcleos sociales elementales sobre los cuales cobre sentido y pueda ser estudiada y comprendida la estructura, el poder y los flujos que se generen en el interior y hacia el exterior de la formación concreta ${ }^{13}$. A nuestro modo de ver, la familia y la gens son organizaciones sociales elementales que deben encuadrarse en un poder social superior para cada momento. En este sentido mencionamos los cuatro grados genéricos de la línea evolutiva, desde el origen social hasta la expresión estatal: banda, sociedad segmentaria, jefatura (simple y compuesta) y Estado14; en ellos quedan incorporados los grupos nucleares que para

de la naturaleza de los grupos que preceden a la formación jurídico-política estatal se encuentran, entre otros, LEVY-BRUHL, Nouvelles études sur le plus ancien droit romain (Paris 1947) 33 ss.; LONGO, Corso di diritto romano. Diritto di famiglia (Milano 1946) 1 ss.; DE MARTINO, Storia della costituzione romana, I (Napoli 1958) 14 ss.; SOLAZZI, Diritto ereditario romano (Napoli 1932-1933); PEROZZI, Istituzioni di Diritto Romano, II (Milano 1947) 300 ss.; Le obbligazioni romane, en Scritti Giuridici, II. Servitù e obbligazioni. Milano, 1948, 313 ss.; Dalle obbligazioni da contrato alle obligazioni da delitto, en Scritti Giuridici, II. Servitù e obbligazioni. Milano, 1948, 443 ss.; FREZZA, La costituzione cittadina di Roma e il problema degli ordinamenti giuridici preesistenti, Scritti di Diritto Romano in onore di Contardo Ferrini, I, 1947, 275 ss.; Il consortium ercto non cito e i nuovi frammenti di Gaio, en Rivista di Filologia Classica, 62, 1934, 27 ss.; SCHERILLO-DELL'ORO, Manuale di storia del diritto romano (Milano 1950) 72 ss.; BETTI, La strtutture dell'obbligazione romana e il problema della sua genesi (Milano 1955); LA PIRA, Successione ereditaria intestata e contro il testamento (Firenze 1930). En contra de esta posición caben destacar, ARANGIO RUIZ, Le genti e la città, cit.; DE SANCTIS, Per la scienza dell'antichità. Saggi e polemiche (Torino 1909) 414 ss.; Storia dei Romani, I (Torino 1907) 177; II, 230.; VOCI, Esame delle tesi del Bonfante su la Famiglia Romana Arcaica, cit., 101 ss.; RODRÍGUEZ ADRADOS, El sistema gentilicio decimal de los indoeuropeos occidentales y los orígenes de Roma (Madrid 1948); WIEACKER, Societas, Hausgemeinschaft und Erwerbgesellschft (Weimar 1936); Hausgenossenschaft und Erbeinsetzung. Über die Anfänge des römischen Testaments, en Sonderausgabe aus der Festschrift der Leipziger Juristenfakultät für Heinrich Siber, Leipzig, 1940, 3 ss.; VOCI, Esame della tesi del Bonfante sulla famiglia romana arcaica, en Studi in onore Arangio-Ruiz I, Milano, 1952, 101 ss.; RABEL, Die Erbrechtstheorie Bonfantes, en Zeitschrift der Savigny-Stiftung für Rechtsgeschichte: Romanistische Abteilung, 50, 1930, 295 ss.; ALBANESE, La successione ereditaria in diritto romano antico, in Annali della Università di Palermo, 20.; BIONDI, Obbietto dell'antica hereditas, en Iura. Rivista internazionale di diritto romano e antico, 1, 1950, 150 ss.

11 ARANGIO-RUIZ, Le genti e la città, cit., 11 ss.= Le genti e la città, cit., 110 ss.; KASER, La famiglia romana arcaica, en Conferenze romanistiche dell'Università di Trieste (Milano 1960) 39 ss.; Derecho Romano Privado, trad. esp. Santa Cruz Teijeiro (Madrid 1968) 68 ss.; COLI, Lo sviluppo delle varie forme di legato nel diritto romano (Roma 1920) 24 ss.; Sul parallelismo del diritto pubblico e del diritto privato nel periodo arcaico di Roma, cit., 77; Regnum, cit., 195116.

12 Cfr. nt.5.

13 PERONI, L'Italia alle soglie della storia (Roma-Bari 1996); Formazione e sviluppi dei centri protourbani medio-tirrenici, en Roma, Romolo, Remo e la fondazione della città, 2000, 26 ss., reconoce la familia como célula constitutiva de la sociedad en todos sus niveles.

14 Esta clasificación puede considerarse, siguiendo a RIBAS ALBA, Origen del Estado en Roma (Madrid 2018) 19, la más común en el estado actual de la investigación. 
nosotros son la familia, no entendida en su concepto moderno, y cuando el estado de la cosa favorezca su aparición, la gens.

La familia, y también la gens, son dos piezas sociales que, para entenderse en plenitud, sobre todo la primera, no pueden estudiarse en exclusivo aislamiento a pesar de que este haya sido experimentado en determinadas zonas, por concretas circunstancias y para determinados individuos. De este modo entra en juego el crecimiento de la sociedad fruto del instinto reproductivo humano y de la adhesión al grupo de miembros extraños. La consecuencia de este dinamismo es el crecimiento y decrecimiento. En el primer supuesto se produce, tarde o temprano pero no más allá de dos generaciones, una fragmentación o escisión del grupo familiar que da lugar a otros grupos familiares. En el segundo supuesto, que puede producirse por circunstancias extrañas como epidemias, accidentes grupales o conflictos con otros grupos, la comunidad familiar se reduce manteniéndose o desaparece ${ }^{15}$. Pues bien, la familia y la gens más que grupos sociales, que lo son, deben ser entendidas como un modo de articular el poder dentro de un grado o nivel concreto de sociabilidad, siendo instrumentos tan naturales y tan lógicos que se mantienen a lo largo de la evolución social adquiriendo, en sentido estricto, la expresión «grupo social» solo cuando se hayan encontrado en estado de aislamiento pues ahí no son un modo de articular el poder sino la forma y nivel social únicos en los cuales prevalece la condición de formación social frente a la de modelo de articulación social. En la familia y en la gens la nota más importante no es su condición de sociedad sino su capacidad de organizar la sociedad, que en último extremo es tal porque están correctamente distribuidos sus elementos mediante el útil familiar y gentilicio. La familia y la gens son la herramienta que ordena el caos que se deriva del instinto social del hombre, es decir, el hombre concibe la sociedad como conjunto y la materializa utilizando una herramienta que declara cómo y de qué manera van a resultar socializados, es decir, que ordena las relaciones y distribuye el poder. Para todo ello el papel de la cosa colectiva es fundamental pues el propio poder que se pretende racionalizar es un «patrimonio colectivo» que existe en tanto la voluntad de los miembros se hace positiva respecto a lo que llamamos sociedad. Asimismo, la subsistencia, idea o aspiración fundamental de la sociedad que Morgan ${ }^{16}$ sitúa como primer grado de la formación gradual y como desarrollo subsiguiente de la idea y necesidad humana, exige de unas artes que la satisfagan. Para ello se precisa un material y una conciencia de actuar en beneficio del grupo creado, así la cosa es el material y el uso colectivo, soportado en satisfacción de la supervivencia, la conciencia de grupo de modo que podemos incluso decir que la cosa de uso colectivo crea conciencia de grupo sin profundizar por el momento en esta cuestión.

Tras plantear este recorrido, en el que ha sido inevitable introducir la cosa de uso colectivo y algunas ideas sobre la misma, el primer interrogante que nos formulamos se cuestiona si en algún momento la familia ${ }^{17}$ pudo estar, aunque sea por breve tiempo, aislada.

\footnotetext{
15 Sobre los conflictos entre grupos, DIAMOD, El Mundo hasta ayer (Madrid 2013) 45, afirma que el choque entre colectivos puede llevar a la aniquilación de uno de los grupos.

16 MORGAN, La sociedad primitiva, trad. esp. Ediciones Endymión (Madrid 1987) 79.

17 Entendemos por familia la expresión inmediata del acuerdo social con sus elementos esenciales establecidos; lenguaje, Derecho y cosa de uso colectivo, sabiendo ya que el uso colectivo comprende todo aquello que es de uso colectivo (casa), de servicio colectivo (defensa pasiva), de acción colectiva (agricultura), de asunto
} 
En el mismo sentido cabe preguntarse ¿para qué momentos histórico-jurídicos son aplicables aquellas fases sociales: banda y sociedad segmentaria? ¿qué grupos nucleares comprendieron cada una de ellas? ¿cómo se estructuraban y organizaban esos grupos? ¿dónde quedaba la cosa de uso colectivo? ¿qué hitos llevan a la sucesión de una fase a otra (vinculo parental/ vinculo territorial)? y si en estos hitos, la cosa de uso común ¿ha tenido algún protagonismo o más bien ha sido protagonizada y su expresión modificada?

En este trabajo intentaremos dar respuesta a estas preguntas para los dos primeros niveles sociales que comprenden la sociedad de banda y la sociedad segmentaria y extraeremos una serie de conclusiones para la cosa de uso colectivo.

Para finalizar este apartado añadimos una última pregunta, que respondemos a reglón seguido utilizando expresiones de Morgan manifestando el motivo de ejecución de esta investigación. Así, ¿ por qué es necesario analizar y comprender los momentos de origen y primer desarrollo social para posteriormente desembocar en un análisis de la cosa de uso colectivo tal y como la entendió el pensamiento romano? Porque las modernas instituciones surgen en el periodo de barbarie, cuyo germen se hereda del anterior periodo llamado de salvajismo ${ }^{18}$. Su genealogía se hace a través de las edades, partiendo de su principio, con las corrientes de la cultura concreta. Incluso podemos atrevernos a reconocer que no es más importante el desarrollo que la cosa de uso colectivo sufre desde su inicio hasta época romana que su propio origen, presente en el seno social, pues ahí es donde hay que introducirse para comprender la tradición posterior romana garantía de los futuros ordenamientos europeos.

\section{Expresión de la cosa de uso colectivo en los primeros niveles de la organización jurídico-política}

\section{III.a) Esquema teórico}

La estructura de este epígrafe queda articulada en función de los dos primeros niveles sociales que atraviesa una organización social — banda y sociedad segmentariasiendo empleados como segmentos temporales donde encuadrar la expresión de la cosa de uso público para la experiencia pre-romana, proto-romana y romana. Asimismo se hará una breve exposición de las notas generales que corresponden a cada nivel de sociabilidad ${ }^{19}$ para proceder a continuación a desentrañar la expresión de la cosa de uso colectivo en los

colectivo (controversias) o de necesidad colectiva (defensa activa). En definitiva, cooperación, solidaridad y comunicación.

18 MORGAN, La sociedad primitiva, cit., 78. Morgan divide la vida humana, en atención a sus progresos en la producción de medios de subsistencia, en tres periodos, salvajismo, barbarie y civilización, con sus respectivos estadios, inferior, medio y superior.; Cfr. ENGELS, Origen de la familia, de la propiedad privada y del Estado, cit., 25 ss.

${ }^{19} \mathrm{~A}$ este respecto, características esenciales de los niveles de sociabilidad, seguimos a RIBAS ALBA, Origen del Estado en Roma, cit.,19 ss., donde adecuadamente va señalando las fases de la organización social hasta alcanzar la forma estatal, si bien nosotros nos detendremos en el segundo nivel, sociedad segmentaria, añadiendo las puntualizaciones que nuestra opinión demande y haciendo encajes con las formas sociales que creemos anteceden a la formación de Roma pues el fin de esta investigación es presentar la base para en siguientes trabajos, conectando el hilo discursivo respecto de la cosa de uso colectivo y sus expresiones, abordar las manifestaciones de esta en los niveles que se aproximan más a la formación del Estado. 
dos primeros ambientes sociales que concluirán, tras el paso por otros niveles, en la formación urbana. Al mismo tiempo mostraremos los trasvases y elementos discriminantes que caracterizan nuestro objeto en cada etapa de modo que podamos comprobar como un fenómeno social, jurídico, económico, vital, a través de las fuerzas y capacidades debidamente articuladas de una formación social alcanza el lugar de reservado a la institución. La consecución de estos objetivos pasará por encontrar en otros ámbitos de estudio la solución al problema, asunto que hemos repetido en anteriores ocasiones si bien su advertencia para impedir una lectura a-jurídica de esta parte de trabajo y del trabajo en su conjunto.

III.b) Sociedad de banda y cosa de uso colectivo

Durante la era paleolítica, caracterizada por la piedra tallada, la depredación y el nomadismo ${ }^{20}$, así como por un incipiente arte rupestre, el hombre estaba organizado en bandas ${ }^{21}$. Su estructura interna la componían familias nucleares que según Murdock ${ }^{22}$, tras comparar un numero equivalente a doscientas cincuenta sociedades, la convertían en ley universal para las estructuras sociales de todo el planeta. Este esquema familiar se dio en todas las sociedades humanas para ese estado de desarrollo social, cada una con su propio elemento diferenciador pero enmarcadas dentro del prototipo observado: padre, madre e hijos; hecho que vinculamos con la cosa de uso colectivo, que tiene presencia universal en todas las sociedades conocidas en atención a su configuración como necesidad social, fundamento social y modo efectivo e inmediato de expresión del nuevo grupo.

En la categoría social de la banda o sociedad de banda creemos, en lo que respecta a su unidad o colectividad, que encuentra su antecedente en la sociabilidad animal de sus antepasados primates con el añadido de la moral y el Derecho como rasgos de ruptura cultural con el estado anterior. De este modo, la familia ${ }^{23}$, que ahora es nuclear y da relevancia tanto a la línea materna como paterna, nunca, salvo excepciones de tipo ambientales, pudo permanecer aislada, y de hacerlo el paso de dos generaciones la convierte inmediatamente en un elemento que integra un nivel social superior que no es otro sino la

20 Acerca de las formas de desarrollo vital, MARX, Formaciones económicas precapitalistas. Edición E. Hobsbawn (México 2011), 68, la vida pastoral, o más en general el nomadismo, constituye la primera forma de los modos de existencia, en la cual la tribu no se instala en una sede determinada, sino que aprovecha para el pastaje lo que va encontrando.

${ }^{21}$ Las notas que informan la banda son, siguiendo a RIBAS ALBA, Origen del Estado en Roma, cit., 19, la división del trabajo por sexos, el ejercicio de la caza, pesca y recolección, flexibilidad en su composición, si bien no más de cien individuos, estructura interna articulada en familias de tipo nuclear con posibilidad de formaciones de familia extensa y vínculo de unión basado en el parentesco de carácter bilateral que da la misma importancia a la línea paterna que a la materna.

22 MURDOCK, Social Structure (New York-London 1965) 2 ss.

23 Son sociales algunos animales como afirma Aristóteles como la abeja, de igual modo poseen esta característica los primates. Arist. Poli.; I. 2. 1253.: La razón por la cual el hombre es, más que la abeja o cualquier animal gregario, un animal social es evidente: la naturaleza, como solemos decir, no hace nada en vano, y el hombre es el único animal que tiene palabra. La voz es signo del dolor y del placer, y por eso la tienen también los demás animales, pues su naturaleza llega hasta tener sensación de dolor y de placer y significársela unos a otros; pero la palabra es para manifestar lo conveniente y lo dañoso, lo justo y lo injusto, y es exclusivo del hombre, frente a los demás animales, el tener, él sólo, el sentido del bien y del mal, de lo justo y de lo injusto, etc., y la comunidad de estas cosas es lo que constituye la casa y la ciudad. 
banda. Ahora bien, si la sociedad ordenada conoce como primera modalidad asociativa la banda esta experimentó por razón natural el fenómeno de la cosa colectiva.

En este periodo dado el nomadismo y su consiguiente movilidad y dinamismo, los grupos de banda son incapaces de materializar estructuras estables que respondan a necesidades más allá de la propia alimentación (caza/recolección) y protección (cazadores «guerreros» y sacerdotes). No existe la propiedad del individuo ni de la familia con la excepción de sus vestidos, joyas, armas y lugar móvil de refugio que es desmontado y trasportado por el territorio en el que el grupo se desplaza ${ }^{24}$. Sobre este espacio ha sido considerado una especie de «difuso derecho de propiedad-soberanía ${ }^{25}$ » no del individuo o de la familia sino del grupo-banda ${ }^{26}$. El resto de material, siempre móvil, se puede considerar «propiedad» de la banda o en servicio de la banda. Así, dentro de esta, además de la forma social familiar nuclear y extensa, existen otras formas sociales no fundadas en el elemento sanguíneo sino en el religioso o en el económico, como los grupos con fines místicos (sacerdotes) o los grupos de cazadores respectivamente, de los cuales, como centro de demostración y consiguiente imputación del poder saldrán, reforzados por los caracteres religiosos o depredadores, los líderes carismáticos. En el primer supuesto, los objetos de la realidad material, utensilios y ornamentos litúrgico-rituales, no son «propiedad» del sacerdote o chamán sino que este, mediante una facultad de uso que le otorga su saber y estatus social, se sirve de ellos para propiciar a la banda, verdadero «titular», el favor de la deidad o de los antepasados. Asimismo, algunos lugares del territorio, sobre el que la banda se arroga cierto derecho de actividad, tienen la nota de lugares de culto y por lo tanto de uso colectivo o de servicio al grupo. En el segundo supuesto la pieza cinegética capturada por el grupo de cazadores está al servicio de la banda al igual que la propia «organización» de caza. La presa es «propiedad» temporal de toda la banda, el poder que existe sobre ella, singularmente considerada, es colectivo, a pesar de haber sido apresada por un determinado número de sujetos del grupo, y temporal, pues su consumo extingue tal poder sobre el objeto 27 .

\footnotetext{
24 En estos momentos en los que el hombre es cazador-recolector y en consecuencia su supervivencia depende de los movimientos de la fauna y de los ciclos de la flora. Incluso aún hoy en día ciertos pueblos de la llanura mongola se desplazan desmontando sus lugares de habitación o arrastrándolos con los animales de tiro en expresión de su naturaleza nómada.; PABÓN SUÁREZ DE URBINA, Positivismo y propiedad. Estudio sobre la idea de propiedad función social (Madrid 1925) 129, afirma que «todos los objetos de uso exclusivo y continuo estuvieron siempre sujetos a la apropiación personal» excepto el suelo. «Los pueblos cazadores y pastores, en agrupaciones, llevan una vida nómada; y asentados en un territorio le abandonan "después del entero agotamiento de los medios de subsistencia que les da"»; BONFANTE, Forme primitive ed evoluzione della propietà romana (Res mancipi e res nec mancipi), cit., 3, afirma que la propiedad individual sería desarrollada a partir de la propiedad colectiva si bien por vía de una lenta y gradual evolución.
}

25 RIBAS ALBA, Origen del Estado en Roma, cit., 20; 20 nt.9; Cfr. nt.28.

${ }^{26}$ Creemos que el ser humano no puede desarrollar, en esta época, una noción natural de posesión o dominio individual, más allá de los objetos de uso cotidiano y personal. La primera razón para ello está en la pieza de caza o animales cazados, estos son devorados por los miembros del grupo produciendo sobre la cosa cazada no una relación de posesión, sino un instinto biológico. Podría argumentarse que, de reconocer un poder sobre la pieza de caza, debería calificarse como un poder temporal colectivo. Temporal porque existe en tanto la pieza no es deglutida, y colectivo porque a pesar de ser capturada por un grupo de hombres («asociación» de cazadores) dentro de la banda la razón social hace que, sin planteárselo, esa presa sea inmediatamente entregada a la supervivencia colectiva.

27 Los hombres que capturaron una pieza de caza, y dentro de estos aquel o aquellos que otorgaron el golpe de gracia, se mostraron más valientes o pusieron manifiestamente en peligro su vida por la caza del animal, es 
Interesante es la apreciación de un lugar estable donde dar culto a los antepasados que condiciona la vuelta o el no alejamiento del grupo de dicho punto de referencia al tiempo que potencia el vínculo entre banda y territorio, a través del elemento religioso, produciendo así el nacimiento de un lugar colectivo inmueble, estático, del que nadie puede ser excluido, pues creemos que el territorio, considerado en abstracto, a pesar de haber predicado sobre él un «derecho difuso de propiedad-soberanía» del grupo-banda, es más bien un soporte material o físico general donde el grupo desarrolla su actividad ${ }^{28}$. Por lo tanto, dentro de este espacio o realidad natural incuestionable solo el lugar de culto puede ser considerado como lugar colectivo-religioso sancionado, ya que el resto del espacio es dedicado, por la propia naturaleza de la formación social en este periodo, al desplazamiento, la caza, la recolección y el asentamiento, es decir, es aplicado a una necesidad indiscutible para la vida, pues no se concibe ni es posible desarrollar la actividad biológica humana fuera de un soporte territorial ${ }^{29}$. También es preciso tener en cuenta que, aunque el lugar de uso colectivo tenga un fuerte y único carácter religioso, no por ello su «demanialidad» se diluye, pues precisamente su dedicación a los antepasados es lo que provoca un uso o interés colectivo. Los ancestros divinizados lo son de todo el grupo, de la colectividad de la cual se extrae que el lugar sea comunitario y desde aquí que la «demanialidad», unida íntimamente con la religiosidad, radique exclusivamente en el uso colectivo, imprimiendo esta última su carácter sobre el resto del fenómeno. No obstante, debe señalarse que un lugar/espacio religioso no es en sí mismo de uso colectivo perfecto, sino que deberá estarse al grupo superior y a su espacio cultual para catalogar el espacio/lugar como sacro-demanial en sentido estricto ${ }^{30}$.

decir, por la supervivencia del grupo, recibían del poder colectivo en manos del grupo sobre la cosa cazada ciertas partes del animal, como podían ser sus cuernos, piel, cráneo o partes óseas relevantes en reconocimiento a su interés por la comunidad. En efecto, el poder colectivo que el grupo tiene sobre la pieza de caza crea sobre el sujeto beneficiado por su actuación un poder individual posiblemente trasmisible en vida y con seguridad en la muerte sobre otro miembro carismático del grupo o sobre sus descendientes, nosotros nos inclinamos más por la primera, si bien ambas pudieron darse en reconocimiento de una doble posibilidad. El sobrante de restos óseos no entregados por considerarse de poco valor honorifico podía dar lugar a un apoderamiento indiferente por los miembros del grupo para la elaboración de, como hemos indicado, elementos de adorno, añadiendo en este momento, armas de caza, como puntas de flecha o lanza. Estos objetos, por su lógica corta vida, sobre todo de las armas de caza que desaparecían o rompían en la acción venatoria pueden ser considerados como elementos sobre los que existe un poder individual pero supeditado en gran medida al interés colectivo, si bien la obtención de las mejores armas vendría motivada por la efectividad de uso en la caza del animal premiada con aquellas partes honorables de la cosa cazada sobre las que verdaderamente existe un poder individual.

${ }^{28}$ MARX, Formaciones económicas precapitalistas, cit., 69, el territorio es material de trabajo y la sede o base de la entidad comunitaria. En nuestra opinión, el territorio será material de trabajo con el sedentarismo mientras que en nomadismo es soporte, base o sede material del grupo.

29 Para estas comunidades humanas, fuera de los elementos móviles de su grupo y de aquellos externos que sirviesen para la supervivencia y el culto como ríos, fuentes o bosques el resto de realidades carecían de importancia y debemos catalogarlas como una especie de res communes universi. Sobre las res communes universi se puede predicar en cierto sentido una comunión universal de todos los hombres lo que excluye cualquier tipo de propiedad, vínculo jurídico o consuetudinario sancionado. Cfr. BONFANTE, Forme primitive ed evoluzione della propietà romana (Res mancipi e res nec mancipi), cit., 2.

30 Adviértase que los grupos sociales inferiores que se enmarcan en el ámbito de una formación social superior pueden poseer, como así ocurre en época precívica con la familia o la gens, sus propias divinidades quedando su culto reservado a los grupos concretos. Sobre la diferencia entre sacra publica y sacra privata, vid. Festo, Lindsay, 284 s.: Publica sacra quae publico sumpto pro populo fiunt, quaeque pro montibus, pagis, curis, sacellis: at privata, quae pro singulis hominibus, familiis, gentibus fiunt. Ahora bien, tanto en uno como en otro el 
De nuevo volvemos sobre la cuestión de la cosa y su relación con el ser humano. Reconocer una «propiedad» individual, familiar y colectiva implica habilitar un mecanismo para su protección de modo que el elemento jurídico que recordemos con Fernández de Buján, A. ${ }^{31}$, es lo «coercible exteriormente por medio de los órganos del Estado» u otra organización social, en este caso la banda, está presente en los orígenes sociales, no como teoría general, sino como herramienta ante el supuesto concreto ${ }^{32}$. Así, la cosa de uso colectivo en los orígenes de la sociedad para su primer nivel muestra seis notas informadoras necesarias para comprender sus evoluciones posteriores:

1. La cosa de uso colectivo es aquel material del que usa y disfruta un nivel social concreto (cosa de uso colectivo perfecta), de modo que su comprensión y estudio debe hacerse desde ese estadio especifico, salvo que consideremos un modo social concreto, como la familia, de forma aislada. En este caso su usuario es la banda, mientras que la familia a la que reconocemos una titularidad familiar sobre cosas muebles posee cosas de uso colectivo intracomunitario (cosa de uso colectivo imperfecta), si bien en casos de necesidad limitadas al servicio del grupo.

2. La primera expresión material de la cosa de uso colectivo, que trae causa del nomadismo, está en objetos muebles, no en la tierra que es, en nuestra opinión, para este periodo, mero soporte material.

3. La cosa de uso colectivo tiene un estrecho vínculo con el elemento religioso, tanto en aspecto mueble (utensilios), como en el inmueble pudiendo ser el lugar de culto de los antepasados la primera expresión sancionada de un espacio inmueble de uso colectivo donde la protección jurídica se mezcla con el elemento religioso en unidad.

4. La cosa de uso colectivo coexiste con la cosa de uso individual personalísima del individuo o del grupo familiar que siempre es de naturaleza mueble e inconsumible (vestido, ornato, armas, cabañas).

5. La cosa de uso colectivo mueble o el asunto de uso colectivo, como la caza, propicia el nacimiento de los primeros líderes políticos que, junto con el líder religioso surgido también de un asunto de uso colectivo (religión), detentaran el poder, si bien temporal, y la guía del grupo.

6. Una concreta expresión de la cosa de uso colectivo junto con una concreta expresión de la forma social, familia nuclear, son identificables para toda la humanidad sin distinción en el nivel social de banda; y pueden ser apreciables en toda sociedad independientemente del lugar geográfico siempre que se encuentre en estado de banda. Los caracteres que la informarán serán los mencionados en las conclusiones

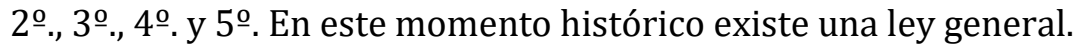

Así, pues, debemos indicar en último lugar la condición de la cosa de uso colectivo para este periodo primitivo. El origen de tener alguna característica debe ser aquella de lo móvil y dinámico. Las cosas de uso colectivo responden a las necesidades primarias del

uso colectivo es advertible si bien en los grupos inferiores es una expresión ad intra o imperfecta mientras que en el grupo superior es global o total y perfecta.

31 FERNÁNDEZ DE BUJÁN, A., Derecho Público Romano, cit., 55.

32 RIBAS ALBA, Origen del Estado en Roma, cit., 23, habla de sanciones y castigos tanto en el ámbito familiar como en el ámbito de la banda, como el ridículo, el ostracismo y la muerte. 
hombre en sociedad, biológicas y no biológicas. Lo jurídico, lo político, lo moral y lo económico son expresiones de lo social aun en su primera forma. Si estas cuatro fuerzas modelan una sociedad de la mano de sus integrantes, las cosas de uso colectivo que se ven involucradas en mayor o menor grado en cada una de ellas responderán solo ante la agrupación humana organizada, es decir ante la sociedad, el grupo, la comunidad. No obstante, las cosas de uso colectivo no son en este momento una institución sino una espontaneidad, una respuesta natural de la inocencia primitiva del ser humano que viene reforzada por el lazo social cuya vida comunitaria bien puede describirse con las palabras del Apóstol: omnes erant pariter et habebant omnia communia et sumebant cibum cum exsultatione et simplicitate cordis ${ }^{33}$.

La cosa de uso colectivo en la sociedad de banda es un fenómeno, un hecho, una realidad que ha pasado de lo ideal a lo material en el momento de formación social sistemática. Podría decirse que la cosa de uso colectivo caro factum est sin elaborarse una conciencia y un pensamiento jurídico o económico sobre la misma. Ella es contemplada como un objeto que sirve al grupo, ante el cual todos los miembros pueden interponer y satisfacer su necesidad siempre que esta no suponga un peligro o perjuicio para la colectividad. Así el fenómeno de la cosa de uso colectivo es en la banda una realidad beneficiosa que gracias al acuerdo social es materializa y puede ser disfrutada por sus miembros, si bien al mismo tiempo la cosa de uso colectivo o su expectación favorable ha sido y es un requisito clave para el nacimiento social ordenado lo que encumbra al fenómeno a una importancia tal que es inequívoco que no se haya previsto, desde su nacimiento, en mano del grupo un modo de actuar, el Derecho, para los casos en los cuales la cosa sufra un atentado desde cualquier ángulo. Podemos suponer que el lugar de culto donde moraban los antepasados, como lugar religioso, por la deidad que lo es del grupo, y colectivo, estaba protegido por la fuerza de los ancestros deificados y por la fuerza de la sociedad, en este segundo caso es donde debe comprenderse el Derecho, pues como señala Ribas Alba ${ }^{34}$ un conjunto de sanciones y castigos es la señal inequívoca de lo jurídico, ahora bien para captarlo debe observarse en unidad con la sanción que impone la deidad, obteniendo así el marco completo del Derecho para esta época que es en gran medida sacralizado ${ }^{35}$. Lo mismo podía suceder en los casos en que una cosa de uso colectivo familiar (imperfecta) o de banda (perfecta) sufría una violación; en estos casos la familia o el grupobanda desplegaba su sistema de sanciones ${ }^{36}$.

Sabemos que la cosa de uso colectivo en la sociedad de banda es un fenómeno que ha pasado de lo ideal a lo material, en consecuencia el grupo se ve en la obligación, debido a

\footnotetext{
33 Act. Apost. 2. 44-46.

34 RIBAS ALBA, Origen del Estado en Roma, cit., 23.

35 FERNÁNDEZ DE BUJÁN, Derecho Público Romano, cit., 41, señala que en la época arcaica Derecho, religión y moral se encuentran entrelazados y, en parte, mezclados, y solo con el paso de los siglos se produce, de forma progresiva, la separación de las respectivas esferas.; Vid. sobre el elemento religioso y divino, su interrelación e influencia para caso romano, FERNÁNDEZ DE BUJÁN, Derecho Privado Romano. Décima edición (Madrid 2017) 27 ss.; KASER, Religione e Diritto in Roma Arcaica, en Annali dei Seminari Giuridici dell'Universita di Catania, 1948-1949, 77 ss.

36 Cfr. HOEBEL, The Law of Primitive Man. A Study in comparative legal Dynamics (Massachusetts 1964) 302.
} 
la concurrencia del uso de cada uno de los sujetos sobre la cosa, de establecer un sistema de sanciones que garanticen su labor, es decir, su finalidad, que no es otra que la supervivencia de la organización jurídico-política en un nivel de sociabilidad. Este propósito, la supervivencia, presente siempre en cualquier nivel social pero de un modo más acentuado en el origen y primeros pasos, provoca que la cosa colectiva, conducto que conduce hacia ella, se encuentre en estrecho vínculo con esta y por ella con la sociedad que la observa como algo fundamental y propio. Este rasgo será capital y una de las esencias de la cosa colectiva a lo largo de la historia jurídica de Roma que no obstante ira perdiendo su fondo a causa de la culminación del proceso de concentración de poder en los últimos emperadores, donde se confundirán las cosas de la sociedad y las cosas del jefe de la sociedad, sociedad y jefe serán lo mismo ${ }^{37}$. Sin embargo, estas ideas serán retomadas y tras la Revolución Francesa se construirá una noción de cosa de uso colectivo que otorga el sentido original a este instituto, sentido que fue perfeccionado con los adornos de la ciencia jurídica romana y que son captados, aún hoy, en plena época contemporánea.

Junto a las anteriores conclusiones podemos añadir tres nuevas que vienen a completar los rasgos identificativos de la cosa de uso colectivo en el origen y la sociedad de banda.

1. La cosa de uso colectivo es un fenómeno, un hecho, una actividad de la cual irán surgiendo concepciones más perfectas.

2. La cosa de uso colectivo está protegida por el Derecho a través de un sistema de sanciones.

3. La cosa de uso colectivo se encuentra en un estatus superior y queda vinculada al grupo de forma estrecha siendo este creador, administrador, garante y «propietario» de la misma a pesar de que la aplicación del Derecho o ciertos asuntos de uso colectivo sean realizados por sujetos individualizables, que no obstante tienen como punto de referencia siempre a la colectividad de la cual reciben su cometido.

III. c) Sociedad segmentaria y cosa de uso colectivo

El siguiente nivel social donde queda enmarcado el fenómeno de la cosa de uso colectivo es la sociedad segmentaria ${ }^{38}$. En este escalón social los grupos, constituidos en su

\footnotetext{
${ }^{37}$ Cfr. los textos de Gai. Inst.; I. 53.; D. 1. 6. 1. y Inst. Iust.; I. 8. 1. Donde se aprecia la evolución de concentración personal del poder en la figura del emperador. Así, en las Instituciones de Gayo (Gai. Inst.; I. 53.) se habla del pueblo Romano como centro de imputación del poder «sub imperio populi Romani sunt». Conforme avanza el tiempo, D. 1. 6. 2., ya no habla de «imperio populi Romani», sino «sub imperio Romano sunt» el pueblo va siendo desplazado por el príncipe quien va absorbiendo todo el poder. Por último, en una etapa final, en Inst. Iust. I. 8. 1., Justiniano, como cristalización completa de este proceso de centralización del poder en la persona del emperador, refiere «sub imperio nostro sunt». Vid. ORESTANO, Il problema delle fondazioni in Diritto Romano. Parte prima. (Torino 1959) 39.; A pesar de todo este proceso en que la cosa de uso colectivo, junto con otras muchas realidades, va perdiendo su sentido, se puede hablar de supervivencias y decir junto con LAMBERT, La tradición romana sobre la sucesión de formas del testamento ante la historia comparada, cit., 20, que «muchas de las reglas jurídicas», instituciones o fenómenos «conservan su imperio largo tiempo después de la desaparición de su razón de ser». Un rasgo que no desaparecerá a pesar de la concentración del poder es su destino social o público, de otro modo, esta institución, negándose a sí misma, desaparecería como tal.

${ }^{38}$ Este nivel social es conocido también con el nombre de tribu.; Cfr. LAPIDUS, Tribes and State Formtion is Islamic History, en Tribes and the State formation in the Middle East, 2006, 28. REDLICH, International law as a substitute for diplomacy, cit., 1 ss.; Sobre el concepto de tribu para estos momentos sociales, vid. KHOURY-
} 
estrato inferior por varias familias nucleares, «se relacionan» $\mathrm{y}$ «se integran en un plano de igualdad ${ }^{39}$ ». Estos grupos, entre los cuales el más común es la familia extensa, oscilan entre el linaje y el clan, comprendiendo el sublinaje y, como hemos referido, la familia nuclear. Así, el orden social hasta el momento se estructura del siguiente modo: familia nuclear < banda $\rightarrow$ crecimiento y escisión < sociedad segmentaria.

No encontramos para este grado de sociabilidad un jefe supremo que concentre el poder, si bien será inevitable la aparición de personajes carismáticos que sobresalgan sobre el resto de la sociedad. Igualmente pueden surgir segmentos que destaquen sobre los otros, ahora bien, este carisma o destaque tiene un rasgo temporal y en este periodo prima la igualdad y paridad entre grupos frente a la figura carismática ${ }^{40}$. Hay un embrionario elemento personal atrayente.

La organización interna en esta etapa social, en virtud del crecimiento poblacional experimenta la estructura de la familia amplia que es, en nuestra opinión, el germen y el precedente de la sociedad gentilicia. Además, como hemos referido, comprende, por orden numérico ascendente, la familia nuclear, la familia extensa, el sub-linaje, el linaje y el clan en los cuales, sin excepción, existe una cabeza y una estratificación que se corresponde con la del resto de grupos (segmentos) que integran la sociedad segmentaria. Con palabras de Sahlins ${ }^{41}$ cada grupo «es el duplicado estructural del otro». La igualdad que se predica entre segmentos permite que podamos hablar de una idealidad social, donde no existen centros de poder formalizados $u$ oficializados superiores al segmento si bien estos en su interior hallan la estratificación y jerarquía, no obstante, transitoria, que no existe fuera ${ }^{42}$. Este aspecto es, a nuestro juicio, el que permite cierta estabilidad de la sociedad segmentaria, de otro modo sería necesario un poder superior segmentario institucionalizado que organizase la comunidad.

A su no especialización exterior e igualdad se une, como nota fundamental el parentesco unilateral, dándose casos es los que se escoge la línea materna y en otros la paterna, así como el conocimiento de la agricultura y la ganadería al tiempo que se

KOSTINER, Tribes and the complexities of State formation in the Middle East, en Tribes and the State formation in the Middle East, cit., 5 ss.

39 RIBAS ALBA, Origen del Estado en Roma, cit., 53.

40 Estos personajes o grupos carismáticos obtienen la característica señalada por sus habilidades respecto a un asunto de uso o interés colectivo como la caza o las dotes mágico-religiosas que establecen conexión con el mundo de los ancestros y las deidades.

41 SAHLINS, The segmentary lineage: an organization of predatory expansion, en American anthropologist, 63, 1961, 322 ss.= Il lignaggio segmentario: una organizzazione per l'espansione predatoria, en FABIETTI, Dalla tribù allo Stato. Saggi di antropologia política (Milano 1991).

42 La primera especialización, jerarquía y división del trabajo se dio en la sociedad de banda, donde la diferenciación tomo un sesgo marcado por el sexo. ENGELS, Origen de la familia, de la propiedad privada y del Estado, cit., 202 ss., tomando como metodología la comparación con la tribu de los pieles rojas de América refiere que la única división del trabajo es la que toma como elemento discriminante el sexo.; MANN, The sources of power (Cambridge 1986) 37 ss., habla de divisiones por sexo y edad en las sociedades segmentarias o tribales.; RIBAS ALBA, Origen del Estado en Roma, cit., 63, reconoce que dentro de la familia nuclear o extendida se dan relaciones de jerarquía fundadas en la desigualdad por edad y sexo.; en este sentido es de advertir como una figura paterna o materna se imponía sobre la descendencia y como con el trascurrir del tiempo la figura patriarcal será la depositaria del poder absoluto familiar.; BURBANK-COOPER, Imperios (Barcelona 2010) 24, habla para la sociedad segmentaria o tribu de una división según sexo, estatus y parentesco. Como aclaración esta situación se produce en el interior de cada uno de los segmentos. 
complementa con actividades que traen causa de la edad anterior como la caza, la pesca y la recolección ${ }^{43}$. El impacto principal que supone este último acontecimiento histórico provoca que la sociedad segmentaria pura ${ }^{44}$ sea catalogada como una sociedad sedentaria donde se forma un centro residencial y urbano. Esta estabilidad residencial estimula el interés de la sociedad hacia el control de un territorio y favorece la creación de reglas jurídicas más perfectas que quedan unidas al sedentarismo al comprender que un lugar específico será el espacio donde ha de desarrollar su existencia la sociedad. De este modo la normatividad comienza a comprender una realidad material estática, estable e interior y exterior al segmento que provoca una concentración de esfuerzos en la creación de un Derecho ${ }^{45}$, que en esta época es consuetudinario, pues este ya no va a regular algo móvil y dinámico sino aspectos que a pesar de su dinamicidad ostentan un elemento superior de estabilidad ${ }^{46}$. En momentos de nomadismo sucedía algo diferente. La normatividad podía, en ciertos aspectos irrelevantes al mismo, ser más flexible o inexistente como sucedía con el extremo inmueble. Esto no debe confundirse con una expulsión de la regulación de los elementos anteriores, sino que este progreso o avance debe entenderse como un asentamiento del Derecho, gracias a una realidad firme e inmóvil, y una perfección del mismo que puede considerarse como la primera y fundamental sobre la que se construirá lo postrero pues de lo móvil se pasa a lo inmóvil, pero de lo inmóvil no se puede avanzar hacia otra realidad. Por lo tanto, lo estático es una expresión suprema que permite establecer los fundamentos de control que irán tomando expresiones distintas conforme se avance en la escala de sociabilidad. El asimiento a realidades materiales estáticas produce la perfección del Derecho al tomar su elaboración un cuidado especial que se proyectará sobre «cosas» que tienen una vocación de perpetuidad gracias al sedentarismo del grupo. Ante toda esta perspectiva la cosa de uso colectivo va adquiriendo rasgos de institucionalización.

En lo que respecta al pensamiento colectivo, la toma de conciencia del grupo va más allá de la mera concepción social, a ella ahora se adjunta el planteamiento de un espacio territorial propio que además de ser soporte material es lugar de habitación estable (aldea) y de subsistencia (terrenos para la agricultura y la ganadería). La construcción de este espacio pasa por la necesidad de trabajos colectivos que adecuen la zona a la nueva necesidad residencial. Estos trabajos realizados por los consociados tienen un fundamento

\footnotetext{
${ }^{43}$ RIBAS ALBA, Origen del Estado en Roma, cit., 54; 56.

44 Hablamos de sociedad segmentaria pura al comprobar la existencia de grupos que combinan el sedentarismo con el nomadismo a lo largo del ciclo anual. Cfr. SAHLINS, The segmentary lineage: an organization of predatory expansión, cit., 322 ss.= Il lignaggio segmentario: una organizzazione per l'espansione predatoria, cit.

45 El papel del arbitraje en este periodo es de suma importancia. En numerosas ocasiones se recurre a su empleo que suele ser ejercido por una persona influyente como el chamán, hombres fuertes o en caso de conflictos entre parientes su resolución pasaba por la mediación de un pariente común a los sujetos en disputa. Vid. EVANS-PRITCHARD, The Nuer. A description of the Modes of Livelihood and Political Institutions of a Nilotic People (Oxford 1967).

46 Sobre la creación y evolución del Derecho, KASER, Religione e Diritto in Roma Arcaica, cit., 83, afirma que en el principio el Derecho era creado ex novo, paulatinamente, en atención al caso concreto; solo más tarde viene a resolver los casos idénticos de conformidad con las soluciones precedentes; y solo aún más tarde se desarrolló la norma jurídica desde los «precedentes» judiciales.
} 
de creación de realidades colectivas, así como de trasformación de las mismas, que vendrán a ser destinadas a beneficio y supervivencia del grupo, como por ejemplo la construcción de obras hidráulicas. Estas obras sociales son, en síntesis, la expresión materializada de aquel concepto de cooperación, solidaridad y comunicación que viene a expresarse en un elemento/asunto concreto y necesario para la comunidad: la cosa de uso colectivo. En este sentido podemos afirmar que la solidaridad, cooperación y comunicación, ideal y material, son el apoyo entre los segmentos. Asimismo, las obras comunitarias tienen un componente de exaltación de la unidad social y son termómetro del estado comunitario ${ }^{47}$.

En la dirección de la cooperación juega un papel esencial el jefe de cada grupo que forma la sociedad segmentaria. Puede ser que en este punto se halle el antecedente informe de los patres del caso romano. El grupo de los «patres» formaría una especie de consejo patriarcal en el que serían discutidas y resueltas las necesidades y asuntos colectivos (v. gr. construcción de obras colectivas). Frente a este consejo el papel de la divinidad no pasaría inadvertido. La cosa colectiva era un asunto de suma importancia sobre todo en lo que respecta al elemento fundiario. En este momento debemos considerar la aparición de la tierra como elemento colectivo de la mano de la domesticación de las plantas y los animales. Los grupos que se encuentran dentro de la sociedad segmentaria — familia nuclear, familia extensa, sub-linajes, linajes, clanes- habrían tenido asignado un espacio que es originado y respetado por el resto de grupos en función de la sociedad que forman. No entrando en el fondo de la naturaleza jurídica de estos elementos, que sin duda es privada respecto a la sociedad superior y colectiva respecto a la sociedad disfrutaría a pesar de que el jefe familiar sea quien ostente la facultad de tomar las decisiones que afecten a la misma, lo cierto es que, una vez asignada la tierra, esta deja de ser un elemento colectivo con importancia social directa pues su administración está puesta en manos de los grupos menores. Al tiempo que esto acontece comienzan a adquirir superior preocupación el resto de realidades sobre las cuales se predica un uso colectivo puro como puede ser el propio trazado de la aldea, sus defensas, sus espacios religiosos y los espacios fundiarios que no han sido asignados sino reservados en servicio común como bosques, pastos o aguas de importancia vital, así como construcciones que requieren la mano colectiva ${ }^{48}$.

La creación de lugares o espacios delimitados tiene dos consecuencias esenciales que van a condicionar e informar la cosa de uso colectivo en periodos posteriores. Se produce en esta etapa un perfeccionamiento total de la cosa colectiva. Esta deja estar vinculada a un elemento móvil y se aferra a un espacio material fijo produciendo progresivamente un conjunto de reglas que regulan su figura ${ }^{49}$. Además, se establece una unión, aun si cabe, más íntima entre sociedad y cosa colectiva. La sociedad de banda poseía cosas de uso colectivo si bien su naturaleza mueble provocaba un desgaste y una

47 Cfr. MARX, Formaciones económicas precapitalistas, 70.

48 En este momento la aldea aparece como un elemento accesorio a la tierra. Es la tierra como medio de producción que satisface de modo admirable la supervivencia quien favorece el asentamiento, y no el asentamiento quien favorece la percepción de la tierra como un medio de producción.; cfr. MARX, Formaciones económicas precapitalistas, 71.

${ }^{49}$ Este es el fenómeno del fundamento y perfección actual y posterior del Derecho que se dará gracias a la estabilidad y fijación de un grupo sobre un espacio concreto (sedentarismo). 
susceptibilidad mayor a la pérdida o a la desaparición. Ahora, en este nuevo nivel social, la cosa de uso colectivo no desaparece ni se extravía, lo único que pudiera sucederle es la interrupción de su destino por causas humanas o naturales, pero siempre con la posibilidad de volver a restituirla a su estado original.

Surge también este momento la monumentalidad que Renfrew ${ }^{50}$ señala sobre los centros ceremoniales y nosotros extendemos a la actividad general de la sociedad tanto en el núcleo residencial como en el territorio que controla. Así, dentro de la zona de aldea se construirían edificios de modo que entre uno y otro quedara un espacio que permitiera y facilitara su accesibilidad (calles) y se reservarían, al igual que sucedía en el ámbito de la economía rural con los bosques y pastos, espacios destinados a la necesidad residencial y política del grupo. De este modo en el espacio urbano se asignó una superficie a cada grupo para construir su residencia al tiempo que se reservó, por decisión social de la comunidad en sus cabezas de grupo, un espacio para la necesidad política y de vida social comunitaria (curias, foros). Un esquema análogo sucedía en el ámbito del espacio económico agrariopecuario; una parte se entregaba en manos de los grupos (linajes, clanes ${ }^{51}$ ) en forma de tierras particulares y otra, como ya ha quedado dicho se consignaba como espacio de uso colectivo y por ello controlado y regulado por el grupo que en este caso estaba personificado en los principales de los grupos-segmentos que formaban la sociedad segmentaria. En realidad, la entrega de una parte del espacio a los grupos segmentarios es la propia entrega a sí mismos, no como sociedad sino como individuos que forman parte de esa sociedad, de una parte del territorio que el grupo social ha alcanzado, por ser sociedad organizada con un nivel de desarrollo adecuado para ello, como elemento propio y primordial. De modo que la propia sociedad es la que sustenta las asignaciones y su disfrute pacífico, el uso privado, así como las reservas y su disfrute pacífico, el uso colectivo. La sociedad segmentaria es el nivel que garantiza, en el ámbito de la cosa de uso colectivo, la continuidad de tal expresión en la línea temporal a la vez que se presenta como titular de la misma.

En cuanto a la relación entre cosa y sociedad debemos hacer la siguiente reflexión. La inexistencia de jefes oficiales superiores a los segmentos produce la percepción de que el estado de la cosa (asignada y reservada) es fruto de un grado social donde un rasgo de igualdad impregna toda su expresión. Las asignaciones se perciben como fruto de un mayor o menor consenso, pero consenso y lo mismo para las reservas. De modo que tanto la propiedad asignada (uso privado) como la reservada (uso colectivo) son creaciones sociales de un grupo institucionalmente acéfalo. En la segunda, por el destino al uso colectivo, la conciencia de identidad social está más acentuada que para la primera pues en ella la identidad solo será grupal o ad intra en atención a la familia, el linaje o el clan del que forma parte. Asimismo, en este estadio, la cosa de uso colectivo será entendida como una creación

50 RENFREW, Prehistory. The Making of the Human Mind (London 2008) 153 ss.

51 RIBAS ALBA, Origen del Estado en Roma, cit., 59, reconoce que «el clan proporciona estabilidad en el sentido que funciona como la estancia superior que reparte los lotes de tierra y cuida de que ningún grupo familiar carezca de una parcela adecuada. El clan como propietario es más bien una forma de garantizar la continuidad del uso por parte de las familias». Sin embargo es la propia comunidad segmentaria, que el autor siguiendo a SAHILINS, The segmentary lineage: an organization of predatory expansión, cit., 322 ss.= Il lignaggio segmentario: una organizzazione per l'espansione predatoria, cit. también denomina tribal, quien «actúa como última titular de los derechos sobre la tierra». 
fija, estable, duradera de un grupo humano con cierto nivel de sociabilidad donde el paso al sedentarismo ha propiciado, con los perfeccionamientos oportunos, que la cosa de uso colectivo que hasta entonces se centraba en lo móvil se enraíce para siempre en lo inmóvil donde encuentra una función social diferente y superior a la desempeñada en el nivel anterior. El paso a lo estático produce una nueva expresión sobre la cosa de uso colectivo que la sitúa como garantía de continuidad social e intergeneracional ${ }^{52}$. El anterior estadio de nomadismo con su cosa de uso colectivo sobre lo móvil no garantizaba, por la propia naturaleza de la cualidad objetiva, una continuidad real del grupo siendo este fácilmente escindible. Ahora la sociedad es sedentaria, busca, encuentra, trasforma y desarrolla un espacio al que le asigna elementos y caracteres que en el estado antecedente no podían darse y sirven, al mismo tiempo, como base donde se apoyan para su ejecución las funciones de continuidad y desarrollo social. Al mismo tiempo la sociedad requiere de un elemento cohesionador que fomente y produzca conciencia de colectividad más allá de los segmentos con el único propósito de la supervivencia y la continuidad para lo cual, entre otros fenómenos, encuentra el de la cosa de uso colectivo cuya expresión en este periodo es fruto de una ordenación igualitaria y de un constante esfuerzo de la potencia social por la mejora de las condiciones de vida de sus integrantes. Además, determinados servicios solo pueden verse satisfechos plenamente en el ámbito del segmento con la colaboración del resto de segmentos que forman la sociedad. Se vuelve indispensable la cooperación para alcanzar objetivos, que serán comunes al confluir en su consecución la unión de los grupos. Dos ejemplos que ilustran esta afirmación son la defensa o ataque y las obras hidráulicas, urbanas o de medios de comunicación. En resumen, la cosa de uso colectivo es su dimensión religiosa ${ }^{53}$, económica y política, busca exclusivamente dos fines por un medio: la supervivencia del grupo y su prolongación en el tiempo a través de una convergencia cohesionadora en su material.

El grupo es el titular primero y último de la cosa de uso colectivo ${ }^{54}$. Además, es su creador y su perfeccionador; es el que usa y el que habilita el uso; es su protector y su peligro; es su dependiente y su dependido; es en definitiva su propio ser y pensamiento social materializado en construcciones concretas de la realidad objetiva. De nuevo este pensamiento y ser no es otro que alcanzar la supervivencia y prolongación del grupo en el tiempo.

Junto a estas ideas debe mencionarse la trasmisión y protección del tipo de uso colectivo y ponerse en relación con la trasmisibilidad y protección de los elementos asignados. La tierra asignada no podía ser transmitida a otro clan o linaje en virtud de la estructura personal interna que presentan los grupos segmentarios y que se identifica con una comunidad formada por vivos y difuntos ${ }^{55}$. Ahora bien su enajenación era posible

52 Sea cual fuere el tipo de sociedad creemos que la continuidad de grupo es un aspecto esencial de la misma.

53 En la dimensión religiosa se da un uso supra colectivo al considerar el linaje o al clan como la suma de sus miembros vivos y difuntos, así el lugar donde confluyen estos es en el espacio reservado al culto divino.

54 MARX, Formaciones económicas precapitalistas, cit., 69, afirma, «la unidad es el propietario efectivo y el supuesto efectivo de la propiedad colectiva, esta misma puede aparecer como algo particular por encima de las muchas entidades comunitarias particulares y efectivas».

${ }^{55}$ Cfr. RIBAS ALBA, Origen del Estado en Roma, cit., 60. 
siempre que concurriesen el consentimiento de una serie de parientes o la adopción del vendedor por parte del grupo comprador. Por su parte la trasmisibilidad en el elemento reservado estaría fuera de todo planteamiento y desde un primer momento ajena a la órbita del pensamiento social e individual. El motivo de esta ausencia cognitiva práctica y real está suscitado por la condición del lugar. En él yace el espíritu social, la esencia del grupo y la garantía de su vida. Del mismo modo que trasmitir un elemento asignado de un grupo a otro sería despojar a los vivos y difuntos de una comunidad específica de su medio principal de subsistencia familiar, la trasmisión de un elemento reservado sería despojar a la sociedad de uno de sus miembros fundamentales o privar a los grupos-segmentos de una supervivencia efectiva y de una prolongación temporal a largo plazo, en definitiva, abrir el camino de la destrucción social, que partiría de lo material y concluiría por lo espiritual llegando a borrar cualquier conquista de expresión colectiva o individual ganada hasta el momento. La única opción que cabe afirmar a este respecto es una redistribución de la cosa de uso colectivo a la que quedará supeditada el elemento asignado siendo sacrificado si este o el espacio que ocupa fuese necesario y requerido para asuntos de interés colectivo.

Respecto a la protección de la cosa de uso colectivo, poniéndola en un estudio comparado con el elemento asignado («propiedad privada») debemos hacer alguna apreciación. El surgimiento del sedentarismo con la domesticación de seres vivos produce el problema de las asignaciones y del consiguiente poder individual sobre las mismas. La producción de estas asignaciones, que se daba en todos los ámbitos familiares, provoca una competencia por poseer más bienes y sobresalir sobre el resto. Estas producciones y sus productores (tierra, ganado) requieren en este momento ser protegidos de la envidia exterior que crea la competencia ${ }^{56}$. De esta forma comienzan a cimentarse estructuras socio-políticas que cumplen con este objetivo como pueden ser las sociedades de jefatura o chiefdom. Ahora bien, dejando a un lado el modelo hacia donde nos lleva este elemento, centremos la atención en la protección de la cosa de uso colectivo. En ella no encontramos la competencia que existe en las asignaciones. Ella sirve, siempre que se haga un uso razonable, a todos por igual. Cada miembro y grupo tiene la misma cosa, no del mismo género con diferente individualidad, sino del mismo género y en una única individualidad. A todos ellos sirve, ya como sujetos individuales, ya como sujetos familiares, ya como sujetos de un linaje, de un clan, de un nivel social. Esta expresión de la cosa no fomenta la dirección hacia formas sociales donde el poder centralizado este para protegerla pues se comprende que de sufrir atentado el perjudicado no es un individuo, familia, linaje o clan especifico, sino la suma de todos ellos, al tiempo que el ofensor, siempre que sea de aquella sociedad, es a la vez ofendido. Así, lo que requiere la cosa de uso común es una estructura de protección no una estructura social superior que la defienda. La misma sociedad que consiguió crear una cosa de uso colectivo con unos rasgos institucionalizados será capaz de su protección en virtud de la propia cohesión, cooperación y solidaridad que esta desprende. De este modo no se requiere un poder centralizado pues la cosa por la bondad de su destino ya produce esa centralización en la plenitud de la sociedad segmentaria cuya

56 Tit. Liv. ab. urb. cond.; I. 6. 4.: Quoniam gemini essent nec aetatis verecundia discrimen facere posset, ut di quorum tutelae ea loca essent auguriis legerent qui nomen novae urbi daret, qui conditam imperio regeret, Palatium Romulus, Remus Aventinum ad inaugurandum templa capiunt.; Cfr. Dion. Halic.; I. 86. 3. 
expresión se concentrará y concretará, en este caso, en una estructura de protección. Lo necesario es el sistema de defensa, el poder centralizado no es requisito para su alcance. Sucede lo contrario en la propiedad asignada, «privada» se requiere un sistema de defensa, pero al mismo tiempo un poder centralizado fuerte que garantice su posesión. En la cosa de uso colectivo no se requiere un poder centralizado fuerte porque la posesión ya está en todos y atentar contra ella es oponerse a toda la sociedad y no a un elemento personal concreto.

Creemos que surgen también en este momento lo que será consagrado en el mundo romano como res mancipi y nec mancipi, que con terminología dispar se encuentra, al igual que la cosa de uso colectivo, en todas las sociedades del planeta ${ }^{57}$. La aparición del elemento asignado y del elemento reservado provoca que en el ámbito familiar se articule al mismo tiempo un elemento asignado, que corresponde con las cosas consumibles y de menos valor, y un elemento reservado que corresponde con el elemento asignado por el grupo suprafamiliar (tierra) y con todo lo que a este sirve (animales de tiro).

Recapitulando podemos extraer un conjunto de cambios revolucionarios que nos llevan a la concepción de la cosa de uso común como fenómeno en camino de institucionalización gracias la domesticación de las plantas y animales. La siguiente lista resume los hitos y los caracteres de la cosa de uso colectivo en el ambiente segmentario:

1. La formación de un centro residencial y urbano alenta que la cosa de uso colectivo alcance fundamentos estables y sólidos, así como su primer perfeccionamiento que es común a toda sociedad sedentaria.

2. La estabilidad del sedentarismo estimula la elaboración de un Derecho más perfecto no basado únicamente en la costumbre que a su vez otorga principios de institucionalización en el fenómeno de la cosa de uso colectivo. (Ley incipiente-cosa de uso colectivo incipiente)

3. La expresión de la cosa de uso colectivo queda vinculada de modo definitivo a la realidad material inmueble.

4. La cosa de uso colectivo no es una realidad material originada por un grupo aristocrático o de jefatura sino que es un hecho social de una sociedad igualitaria, si bien en eminente surgimiento del elemento personal carismático.

5. El titular, creador y perfeccionador de la cosa de uso colectivo en esta etapa es la comunidad segmentaria.

6. Su expresión inmueble se desarrolla en la figura de la reserva tanto en el ámbito de la economía rural (pastos, bosques, aguas) como en el ámbito urbano (trazado urbano).

7. Comienza a expresar un rasgo de monumentalidad, índice de su perfeccionamiento.

8. La cosa de uso colectivo tiene una función de dar continuidad y cohesión al grupo a través de su capacidad de crear conciencia y unidad social.

9. Existe una retrofuncionalidad entre la cosa de uso colectivo y la sociedad de modo que la primera permite la continuidad y cohesión de la segunda y esta posibilita la aparición material de la primera y su consiguiente perfeccionamiento.

57 BONFANTE, Forme primitive ed evoluzione della propietà romana (Res mancipi e res nec mancipi), cit., 216 ss. 
10. La cosa de uso colectivo es intransmisible, en tanto es esencia y expresión de la sociedad y garantía de su desarrollo y continuidad, y superior respecto a los elementos asignados-privados.

Para cerrar este epígrafe debemos hacer breve mención al vínculo parental que no tiene más función que la de determinar grupos a los que entregar el elemento asignado y nada que ver con la cosa de uso colectivo perfecta que sin embargo puede ser utilizada por los grupos en sí mismos y por sus miembros de modo individualizado.

Añadir sobre la monumentalidad de centros religiosos — que trae causa del periodo anterior donde el grupo ya había creado un lugar inmueble único donde se predicaba el uso colectivo junto al religioso- que esta es posible por la existencia de una fase anterior la cual se proyecta en nuestra opinión para este periodo también sobre aspectos del espacio urbano. Complementariamente, al servicio del culto social divino estaba el sacerdotechamán cuyo poder bien puede considerarse como una facultad suprema que se expande sobre todo el grupo ${ }^{58}$. La acefalia de estas sociedades viene así herida de muerte al encontrar un poder, si bien sacral, que cubre todos los segmentos al tiempo que figuras políticas carismáticas comienzan a sobresalir y a apuntar en la escena social, sobre todo en la caza, la guerra y el asunto colectivo, de cuyo ejercicio habilidoso adquirirán su influencia. En numerosas ocasiones ambas figuras, sacerdote y líder político, se concentran en el mismo individuo. Hemos de conectar lo anterior con la cualidad de la cosa o asunto de uso colectivo para engendrar figuras destacables, no obstante, cuando estas comiencen a emerger del seno social y, concretamente de los segmentos, la cosa de uso colectivo ya tendrá los caracteres más arriba sintetizados de modo que de ninguna manera esta es fruto de un poder religioso o político y lo mismo su expresión fundamental y básica. Así, la cosa de uso colectivo es fruto de una sociedad eminentemente igualitaria donde comienzan a despuntar centros personales atractivos que condicionaran la expresión de la cosa, al menos en apariencia, en los siguientes niveles de socialización.

Por último, la unión intima entre sociedad y cosa colectiva, su creación material inmueble, expresión plena, y el ambiente de paridad en el que se produce todo este fenómeno de creación/perfección hace que debamos hablar de una Edad de Oro para la cosa de uso colectivo pues de aquí, aunque sin olvidar la fase anterior ${ }^{59}$, es de donde se tomaran

\footnotetext{
58 Para algunos autores, como FUKUYAMA, Los orígenes del orden político, cit., 98 ss., no existe una deidad de carácter general en esta etapa. El elemento religioso es interpretado como un elemento autónomo junto con el resto de los caracteres como el económico y jurídico. La característica de autonomía y autosuficiencia provoca que el culto sea interior al segmento. Además, la liturgia, que se dirigía a los antepasados, fomentaba la practica cerrada de sus rituales. Nosotros pensamos que debió existir una deidad general que reforzase los lazos entre comunidades más a allá del parentesco. Aunque de admitir su inexistencia inicial, el parentesco produciría por ampliación de la prole y creación de nuevos segmentos que un antepasado primitivo fuese oficializándose como culto de gran parte de los segmentos, que, si bien podían tener cultos menores, un culto superior enmarcaba a todos ellos. A favor de la enervación de este culto jugó el emergente carisma que sobre individuos pertenecientes a un segmento comenzó a destacarse.

59 De la fase anterior podemos y obtenemos supervivencias que nos ayudan a comprender el instituto o fenómenos en etapas perfeccionadas. En este sentido nos hacemos eco de las palabras de LAMBERT, La tradición romana sobre la sucesión de formas del testamento ante la historia comparada, cit., 20, «las instituciones $O$ fenómenos que el progreso de las costumbres y las transformaciones de la vida económica hacen caer en desuso, dejan siempre detrás de sí algunas huellas, y comunican algunos de sus caracteres a las instituciones ofenómenos
} 
los fundamentos y se darán las expresiones particulares por parte de cada sociedad. Hasta este momento parece que hay una ley general que permite hablar de una linealidad en el desarrollo y evolución de la cosa de uso colectivo. A partir de aquí es posible centrarse en el caso concreto romano, en la estructura social, jurídica, económica y política de sus fases precívicas y proto urbanas de modo que extraigamos, con el análisis de estos pueblos y estructuras el porqué de esta institución tan capital para lo que será después la sociedad romana y sus modelos políticos ${ }^{60}$.

El fenómeno/institución de la cosa de uso colectivo mostrará rasgos que vienen de etapas primitivas como es la íntima unión entre sociedad y cosa colectiva, así siguiendo a Lambert, «el procedimiento y los símbolos varían mucho menos deprisa que el fondo del Derecho. El recuerdo de un ceremonial sobrevive de ordinario largo tiempo a la consciencia de su significación primitiva». Aplicando esta reflexión a la cosa de uso común, el recuerdo de elementos sobre los que se ejerce un uso colectivo sobrevive en toda la historia jurídica de Roma si bien su significación primera se va difuminando hasta llegar a un punto en el cual es irreconocible y solo a partir de un estudio comparado con otras sociedades mejor conocidas en sus etapas primitivas y con otros ámbitos materiales puede volver a ver la luz y comprenderse su sentido primigenio, ahora bien básico, clave, vital y esencial.

\section{A modo de epílogo}

El trabajo expuesto es un fundamento académico para poder abordar los siguientes niveles sociales y la expresión que tiene en ellos la cosa de uso colectivo. Dado que a partir de este momento ha llegado a su fin la «ley general ${ }^{61}$ » podremos analizar a la luz de un pueblo concreto, en nuestro caso el romano, la realidad de uso colectivo y comprender de forma absoluta el sentido de este fenómeno que fue impecablemente construido como institución gracias a los conceptos de Derecho y sociedad que elaboró la experiencia y la ciencia romana.

que las (sic) implantan». La cursiva es nuestra y en relación a la expresión «implantan» para una mejor comprensión sería, en nuestra opinión, escribir «suplantan».

${ }^{60}$ LAMBERT, La tradición romana sobre la sucesión de formas del testamento ante la historia comparada, cit., 19.

61 Carácter de necesidad y universalidad. 